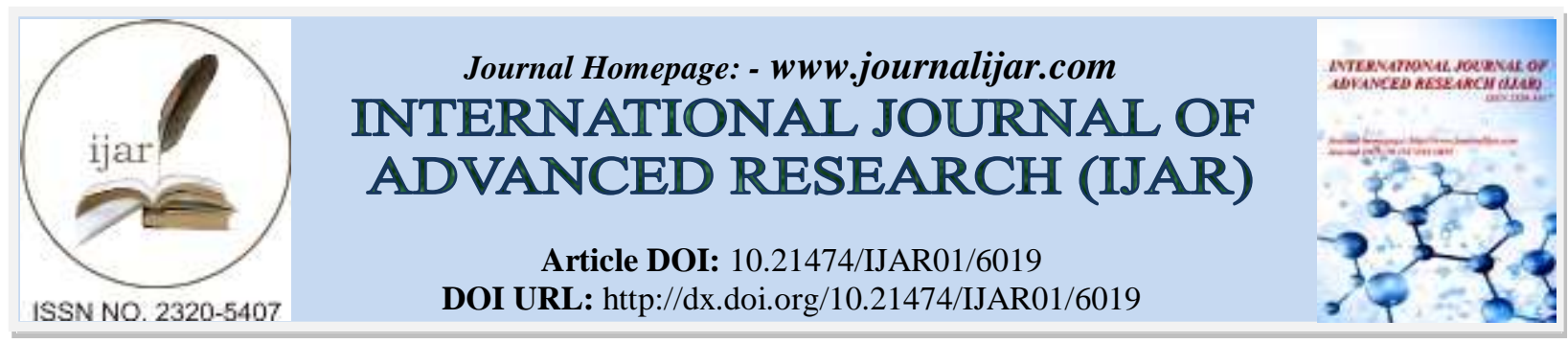

RESEARCH ARTICLE

\title{
ONE CASE OF REFRACTORY STATUS EPILEPTICUS AND AUTOIMMUNE ENCEPHALITIS.
}

\section{Guliko Kiliptari $^{\mathbf{1}}$ and Ia Rukhadze ${ }^{2}$.}

1. Head of Department of critical care., university central clinic after acad. N. Kipshidze ,MD, PhD. Prof.of TSMU (Tbilisi, Georgia).

2. Neurologist, Md, PHD (Tbilisi, Georgia).

\section{Manuscript Info}

Manuscript History

Received: 10 October 2017

Final Accepted: 12 November 2017

Published: December 2017

\begin{abstract}
Purpose: Encephalitis is a severe inflammatory disorder of the brain with many possible causes and with difficult differentiate of diagnosis. Existing criteria for autoimmune encephalitis are too reliant on antibody testing and response to immunotherapy, which might delay the diagnosis. Several particular features raise the suspicion of an autoimmune cause in otherwise unexplained seizure disorders. One of the most important challenges is the elucidation of the causes of seizure disorders.

We presented one case of unexplained coma and refractory status epilepticus. Patient, 20 yars old.men, was admetted in hospital with coma, stable hemodinamics, on mechanical ventilation. On MRI research was discovered existence of inflammatory infiltration.At primery stage , EEG- discovered polymorphic dysrhythmia,bilateral activity,than plural peak shurp-slow wave paroxysms and status epilepticus. It was conducted combinated treatment with anticonvulsive drugs ,Immunoglobulin, pulse corticosteroid therapy with methylprednizolone and plazma exchange therapy.

Conclusion: An autoimmune cause was suspected based on frequent or medically intractable seizures and the presence of neural antibody, inflammatory changes indicated in spinal fluid and on MRI. Patients had abnormal findings on brain MRI, with extensive multifocal or diffuse cortical and subcortical involvement. EEG showed generalized periodic discharges and status epilepticus .

within investigation of $\operatorname{IgG}$ autoantibodies against proteins on the surfaces of neurons, we received difference result from two different laboratory,but refractory status epilepticus,radiological changes ,EEG pattern and progress of illness has indicated autoimmune character of process.
\end{abstract}

Copy Right, IJAR, 2017,. All rights reserved.

\section{Introduction:-}

Encephalitis is a severe inflammatory disorder of the brain with many possible causes and with difficult differentiate of diagnosis. existing criteria for autoimmune encephalitis are too reliant on antibody testing and response to immunotherapy, which might delay the diagnosis.

Corresponding Author:- Guliko Kiliptari.

Address:- Head of Department of critical care. The First University Clinic, MD, PhD. Prof.of TSMU 
Several particular features raise the suspicion of an autoimmune cause in otherwise unexplained seizure disorders.

One of the most important challenges is the elucidation of the causes of seizure disorders. IgG autoantibodies against proteins on the surfaces of neurons were identified as markers and pathogens in autoimmune encephalitides that are accompanied by repetitive focal seizures. the antibodies against surface antigens contribute directly to the disease processes.In particular Anti-NMDA receptor encephalitis is a disease occurring when antibodies produced by the body's own immune system attack NMDA receptors in the brain .In the absence of a reliable biomarker, it is difficult to gain systematic and general insights into these patients.

Because autoantibody test results and response to therapy are not available at disease onset, treatment is based the initial diagnostic approach on neurological assessment and conventional tests that are accessible to most clinicians.

We presented one case of unexplained coma and refractory status epile- pticus .

\section{Case report:-}

Patient, 20 yars old.men,Caucasian was admetted in hospital at 06.07.2017. with coma, stable hemodinamics, on mechanical ventilation (patient was transferred from another clinic) CT of brain could not discovered any pathological changing.MRI within admittion (07.07.2017) was without acute pathological intracerebral changing, EEG- discovered polymorphic dysrhythmia,bilateral activity(Fig.1).
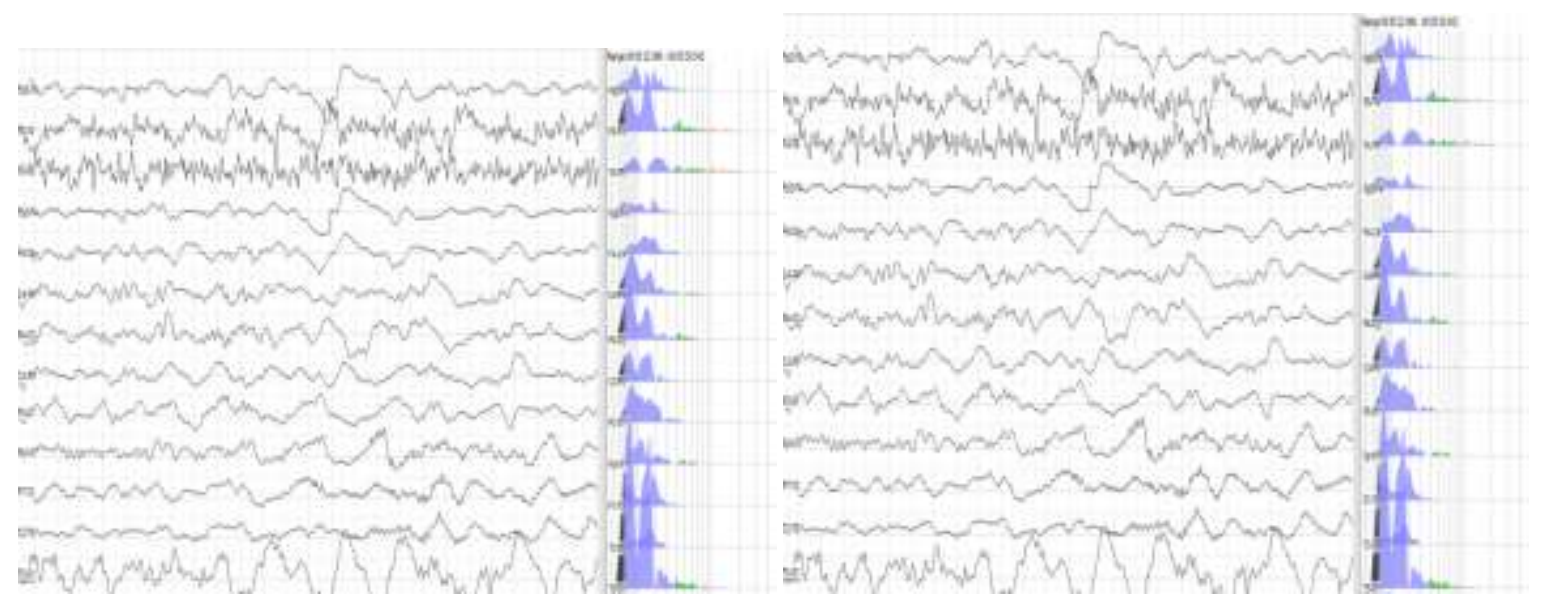

Fig 1:- The patient was examined on viruses, parasites, bacteria.

\begin{tabular}{|l|l|}
\hline Borrelia burgdorferi & IgM -30u/ml, IgG-negative. \\
\hline Mycobacterium tuberculosis & PCR in CSF -- negative. \\
\hline Criptoccocus Ag quantitative analysis & negative. \\
\hline Brucella & IgM -10lu/ml, IgG - negative \\
\hline Leptospira & IgM ,IgG -negative \\
\hline Blood test of gama interferon (ESAT-6,CFP-10,TB7.7) & negative \\
\hline Measles IgG ab - 9600IU/L & N >350,imunity confirmed \\
\hline Measles-Virus - Ak.IgM negative & Normal range -negative \\
\hline $\begin{array}{l}\text { Tick borne encephalitis virus } \\
0.7 \\
\text { Ig M } \\
\text { Ig G } 0.1\end{array}$ & (NORM 0.8-1.1) \\
\hline
\end{tabular}

Patient CSF and serem was examined on autoantibodies against proteins on the surfaces of neurons, in particular for diagnosing of NMDA receptor anti body encephalitis.CSF was sent to the lab at 7.07.17.

Treatment was started empirical, with antiviral(Acyclovir) and antibacterial drugs. After 6 day from the beginning of investigation, autoantibody test result was positive NMDAR AAB in CSF was 1:2, in serum 1:160.(serem and CSF was investigated in Hidelberg laboratory of Limbach)

After 4 day EEG revealed status epilepticus (Fig.2) 


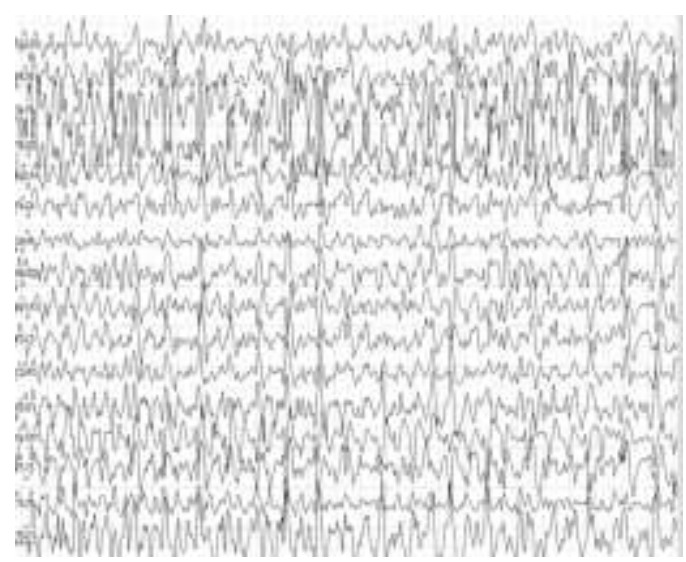

Fig.2:- On Reapeted MRI research (1.07.17) was discovered existence of inflammatory infiltration (encephalitis) in right frontal and parietal lobes and around of hippocampus,intracranial arteriovenous hyperemia.(Fig.3).
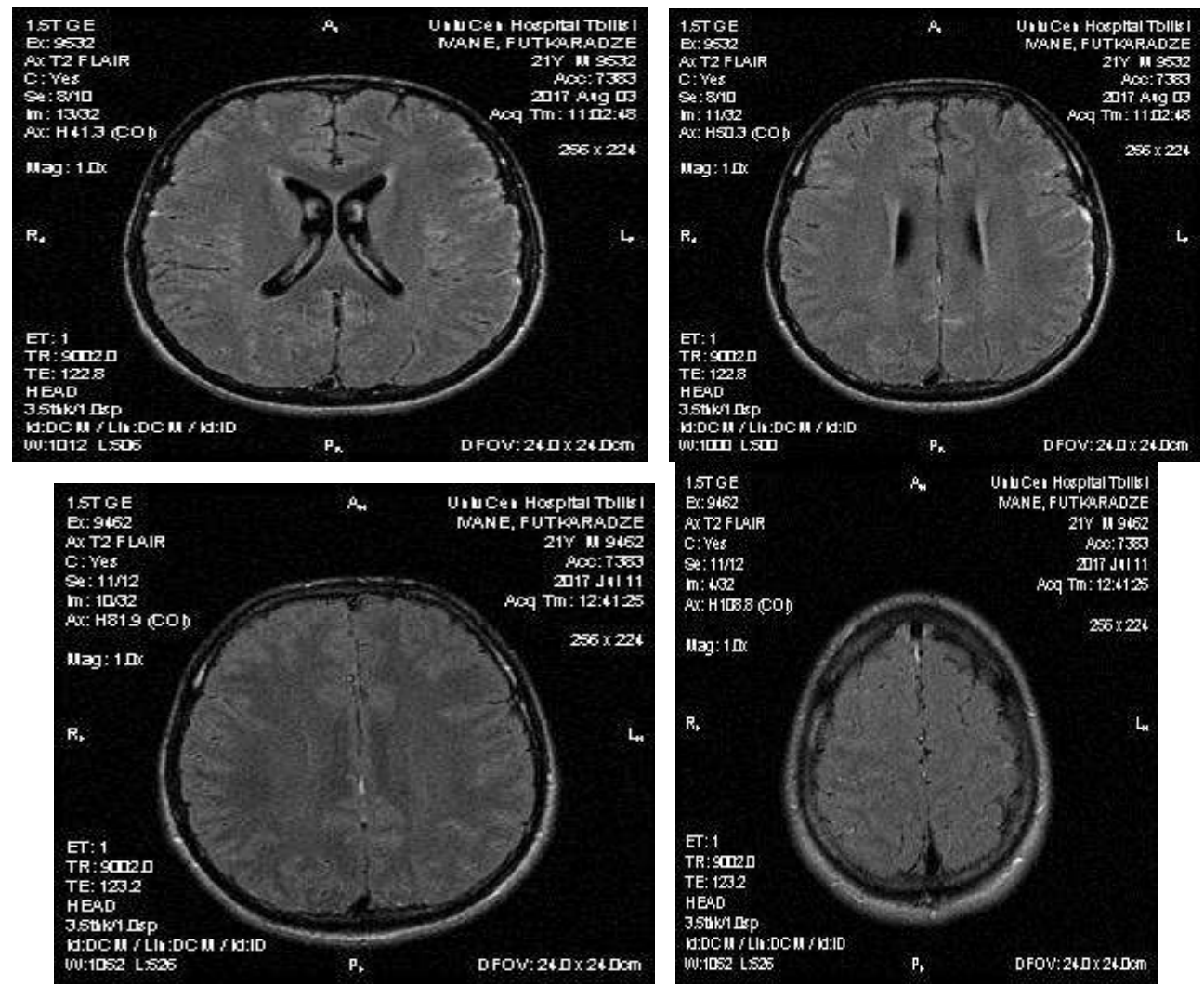

Fig.3:- For status epilepticus was initiated treatment with valproic acid (Depakin),Levetiracetam (Epixx) and carbamazepin.Regardless of this drugs EEG at 17.07 revealed plural Peak shurp-slow wave paroxysms (Fig.4) 

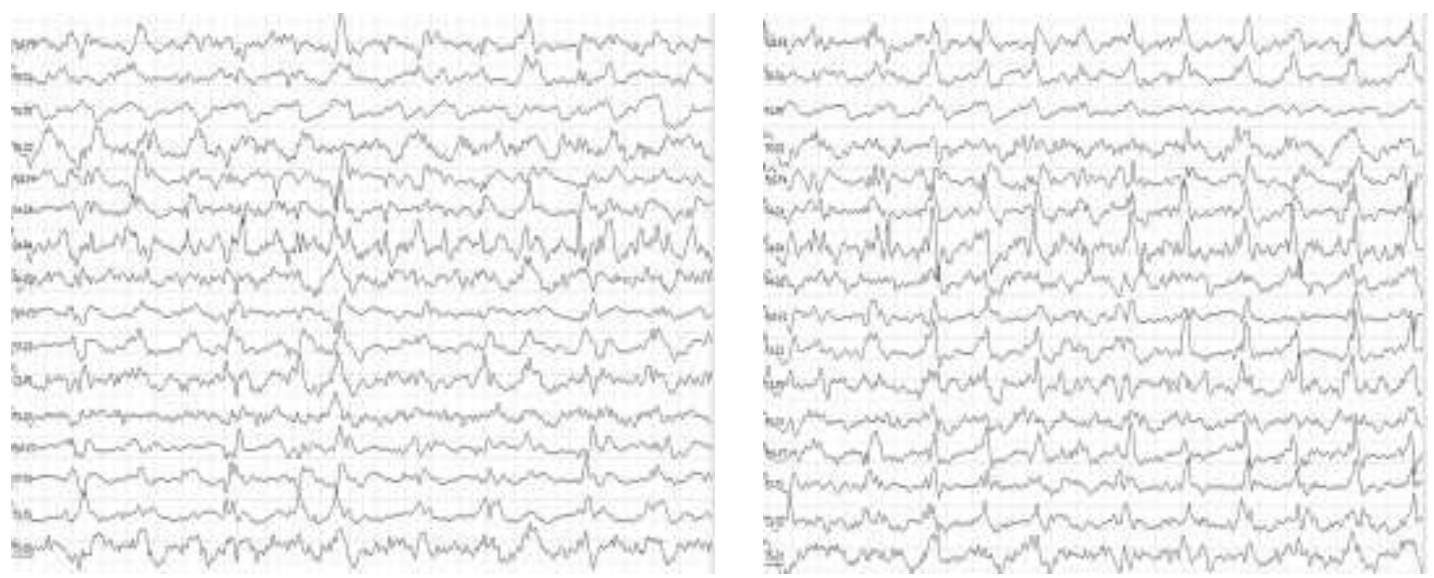

Fig.4:- After detection of NMDAR AAB in CSF, was started immunoglobulin therapy $(0.4 \mathrm{~g} / \mathrm{kg} / \mathrm{day}$ for 5 day). Treatment was lasted with,peroral intake of Epixx and Depakin, intravenous infusion of levetiracetam

(Keppra), Valproate sodium(Depakin ) and intravenous infusion of propofol ( $4 \mathrm{mg} / \mathrm{kg} / \mathrm{day})$, pulse corticosteroid therapy with methylprednizolone. Propofol infusion rate and maximum dosage was selected by considering to avoid of propofol infusion sindrome. We periodically were testing the concentration of anti-conventional drugs in the blood and the dosage was adjusted accordingly.

Additionally was used thiopental infusion and ketamin infusion with dosage $2.75 \mathrm{mg} / \mathrm{kg} . \mathrm{h}(3$ day) ,But the convulsion on EEG was continued.

Epi pattern(27.07.17) had negative dynamics, increased amplitude of epileptic form activities(Fig. 5)
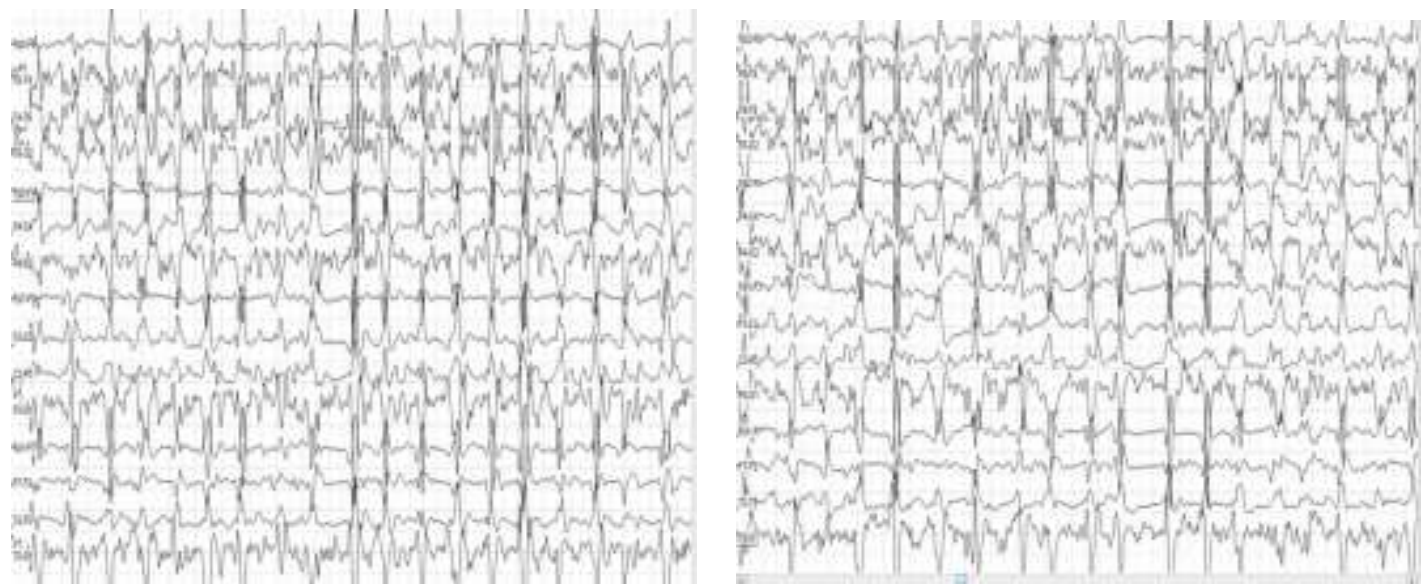

Fig.5:-Plasma exchange (PE) was used as one of the treatment modalities in addition to immunosuppressive therapy, including corticosteroids, intravenous immunoglobulin (IVIG).Regardless of such combined and multilateral treatmnent, EEG (31.07.17) detected negative electrophysiological dynamics (Fig.6), MRI revealed negative radiologic changengs(Fig.6) 

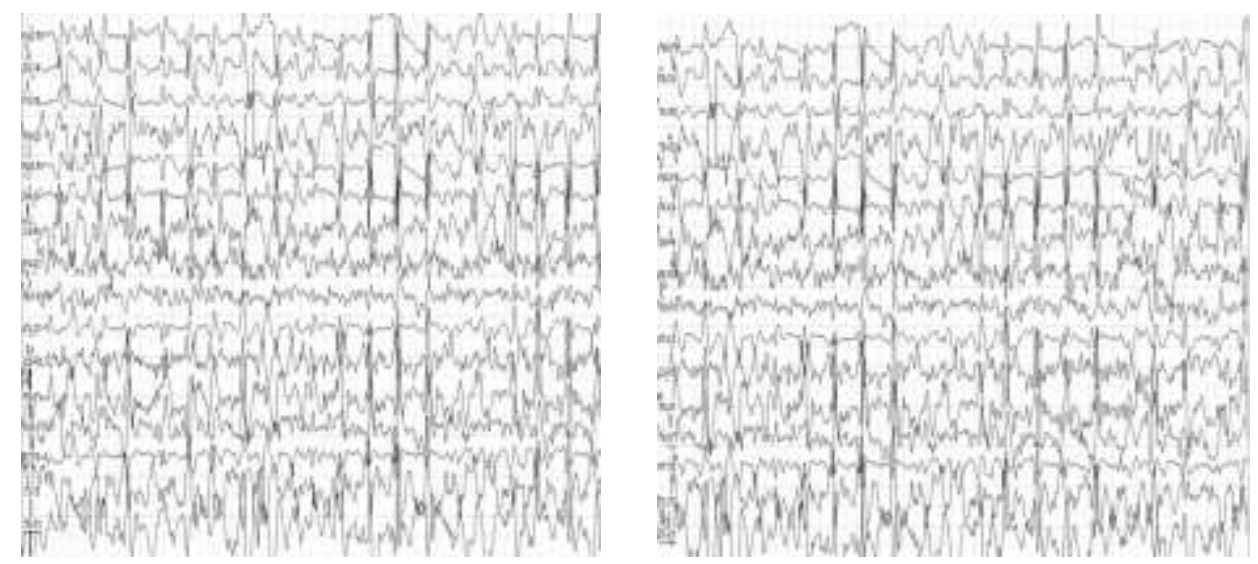

Fig.6:-In large hemispheres, hyperintensiveness of subarachnoid spaces was reduced. However after contrasting, the focal point of contrast substance $w$ as much more manifested in parahippocampus and fragmentately in the area of the membranes (more left).
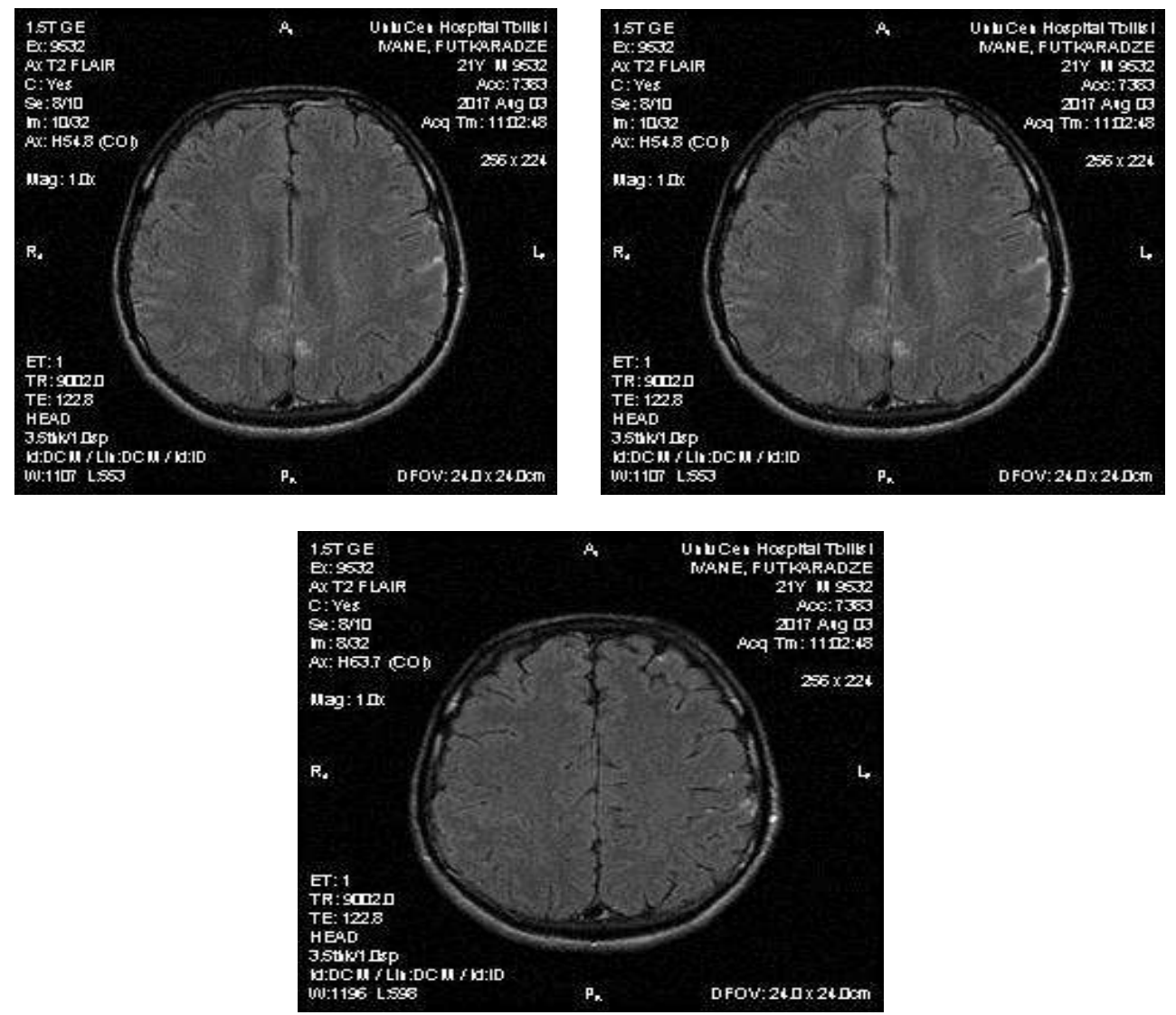

Fig.7:-For maximal captured and decreasion of brain bioactivity was used thiopental with high dose infusion. We achieved absolute decreasion of brain bioactivity and full resolvation of convulsion(8.08.17) 


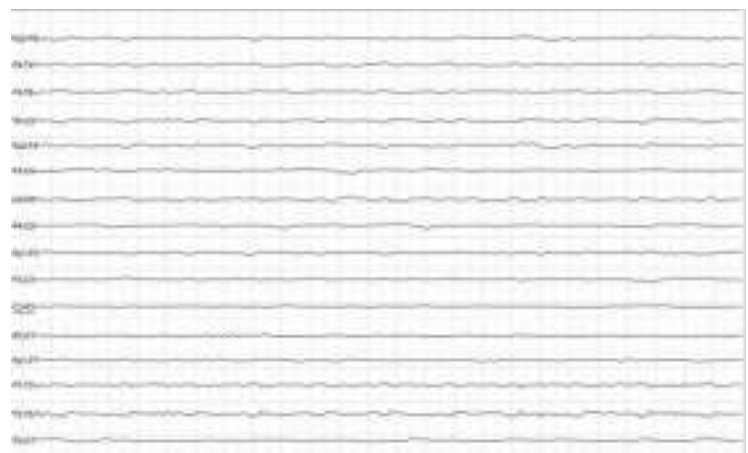

After 48 h.from cessation of thiopental infusion,we received normal EEG and later improvement of MRI parameters. Fig. 8
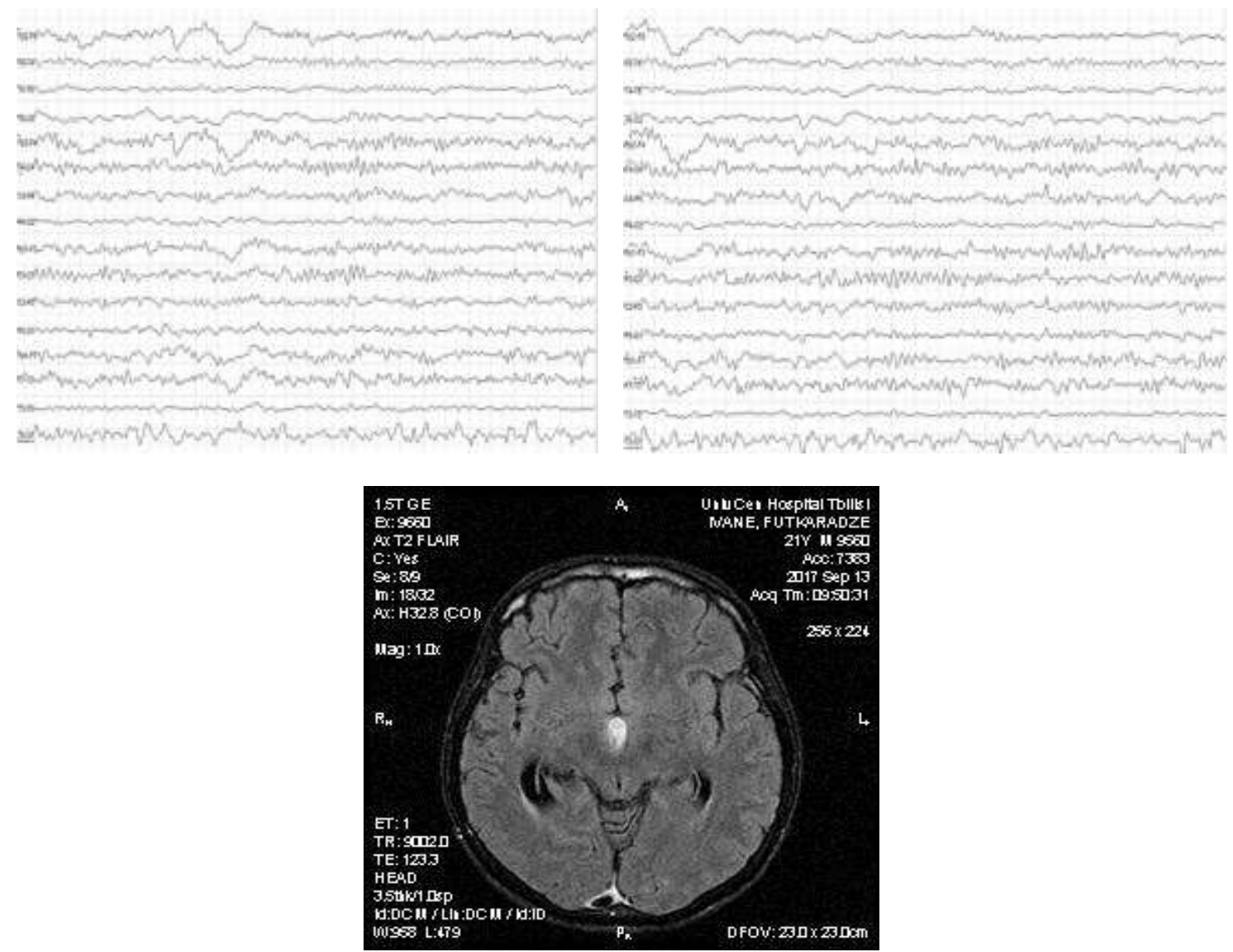

Fig.8:- Patient CSF and serem we were sent to The Austrian Clinical Institute of Neurology.

a) This institute investigated serum and cerebrospinal fluid of our patient for presence of anti-neuronal antibodies.

b) In this laboratory screening for surface receptor antibodies (avidin-biotin-peroxidase technique; rat brain; IIFT Euroimmun) was negative for antibodies such as NMDAR, LGI1, CASPR2, AMPAR, GABA(B)R, and DPPX.A cell-based assay was negative for glycin-receptor antibodies (in-house; GlyR alpha1).

Institute has noticed that negative test result does not exclude autoimmune logically mediated syndromes of other origin. 
Later, after 36 day from admittion patient state has became stable, patient was weaned from artifitial ventilation. The level of consciousness has been gradually improved and finally patient has discharged from hospital .

\section{Discussing:-}

We presented drug-resistant status epilepticus that persisted following the continuous administration of intravenous anesthetics and anticonvulsive drugs for more than several days

Acute onset, resistance to anti-seizure medication, evidence of CNSinflammation was clinical features suggestive of autoimmune epilepsy.

For treatment was used first line therapies -steroids, intravenous immune globulin ,plasma exchange therapy, combinations of these interventions. Anticonvulsive drugs, valproate sodium,levetiracetam , midazolam ,prorpofol infusion and some drugs (carbamazepin,depakin, epixx ) intaked from gastroenteral rute, was not effective.

Many researchers have reported that, during prolonged seizures, the number of activated GABA-A receptors on the postsynaptic membrane gradually decreases, whereas the number of inactive GABA-A receptors increases .These changes cause a significant reduction in the efficacy of antiepileptic drugs (AEDs). Recent studies have found that, during prolonged seizures, when the numbers and activities of GABA receptors gradually decrease,simultaneously, the numbers and activities of glutamatergic NMDA receptors increase, Thus, the commonly used first-line and second-line AEDs gradually fail, often causing RSE and thus providing the possibility of the use of ketamine to treat RSE.Ketamine is a noncompetitive NMDA receptor antagonist that might play a role in treating SE by blocking NMDA receptor-mediated glutamatergic transmission. But After ketamin infusion its anticonvulsant effects has not been reached. For maximal captured and decreasion of brain bioactivity was used thiopental with high dose $(400 \mathrm{mg} / \mathrm{h})$ infusion. We achieved absolute decreasion of brain bioactivity and full resolvation of convulsion.

\section{Conclusion:-}

An autoimmune cause was suspected based on frequent or medically intractable seizures and the presence of neural antibody, inflammatory changes indicated in spinal fluid and on MRI. Patients had abnormal findings on brain MRI, with extensive multifocal or diffuse cortical and subcortical involvement. EEG showed generalized periodic discharges and status epilepticus. Within investigation of IgG autoantibodies against proteins on the surfaces of neurons, we received difference result from two different laboratory,but refractory status epilepticus (Resistance to anti-seizure medication), radiological changes ,EEG pattern and progress of illness has indicated autoimmune character of process.

\section{References:-}

1. Hocker S, Tatum WO, LaRoche S, Freeman WD. Refractory and super-refractory status epilepticus - an update. Curr Neurol Neurosci Rep 2014;14:452.

2. Hunter G, Young B. Status epilepticus: a review, with emphasis on refractory cases. Can J Neurol Sci 2012;39:157-69.

3. Brophy GM, Bell R, Claassen J, Alldredge B, Bleck TP, Glauser T, et al. Guidelines for the evaluation and management of status epilepticus. Neurocrit Care 2012;17:3-

4. Borris DJ, Bertram EH, Kapur J. Ketamine controls prolonged status epilepticus. Epilepsy Res 2000;42:117-22.

5. Tarocco A, Ballardini E, Garani G. Use of ketamine in a newborn with refractory status epilepticus: a case report. Pediatr Neurol 2014;51:154-6.

6. Synowiec AS, Singh DS, Yenugadhati V, Valeriano JP, Schramke CJ, Kelly KM. Ketamine use in the treatment of refractory status epilepticus. Epilepsy Res 2013;105:183-8.

7. Zeiler FA, Kaufmann AM, Gillman LM, West M, Silvaggio J. Ketamine for medically refractory status epilepticus after elective aneurysm clipping. Neurocrit Care 2013;19:119-24.

8. Esaian D, Joset D, Lazarovits C, Dugan PC, Fridman D. Ketamine continuous infusion for refractory status epilepticus in a patient with anticonvulsant hypersensitivity syndrome. Ann Pharmacother 2013;47:1569-76.

9. Kramer AH. Early ketamine to treat refractory status epilepticus. Neurocrit Care 2012;16:299-305.

10. Irani SR, Bien CG, Lang B. Autoimmune epilepsies. Curr Opin Neurol2011;24:146-153 
11. Lee WJ, Lee ST, Byun JI, Sunwoo JS, Kim TJ, Lim JA, Moon J, Lee HS, Shin YW, Lee KJ, Kim S, Jung KH, Jung KY, Chu K, Lee SK. Rituximab treatment for autoimmune limbic encephalitis in an institutional cohort. Neurology 2016;86:1683-1691.

12. Bien CG. Value of autoantibodies for prediction of treatment response in patients with autoimmune epilepsy: review of the literature and suggestions for clinical management. Epilepsia 2013;54(suppl2):48-55.

13. McKeon A, Lennon VA. NMDAR encephalitis: which specimens, and the value of values. Lancet Neurol 2014;13:133-135.

14. Gresa-Arribas N, Titulaer MJ, Torrents A, Aguilar E, McCracken L,Leypoldt F, Gleichman AJ, Balice-Gordon R, Rosenfeld MR, Lynch D,Graus F, Dalmau J. Antibody titres at diagnosis and during follow-up of antiNMDA receptor encephalitis: a retrospective study. Lancet Neurol 2014;13:167-177

15. Höftberger R, Dalmau J, Graus F. Clinical neuropathology practice guide 5-2012: updated guideline for the diagnosis of antineuronal antibodies. Clin Neuropathol 2012;31:337-341.

16. DeSena AD, Noland DK, Matevosyan K, King K, Phillips L, Qureshi SS, Greenberg BM, Graves D. Intravenous methylprednisolone versus therapeutic plasma exchange for treatment of anti-n-methyl-daspartate receptor antibody encephalitis: a retrospective review. JClin Apher 2015;30:212-216

17. Christian G. Bien,1* Martin Holtkamp2 "Autoimmune Epilepsy": Encephalitis With Autoantibodies for Epileptologist ,Current Review, Clinical Science Epilepsy Centre Bethel, Krankenhaus Mara, Bielefeld, Germany,Epilepsy-Center Berlin-Brandenburg, Department of Neurology, Charité - Universitätsmedizin Berlin, Berlin, Germanys, 